Disclosure of Interests: None declared

DOI: 10.1136/annrheumdis-2019-eular.8621

\author{
SATURDAY, 15 JUNE 2019 \\ 09:00:00 - 10:30:00
}

\section{Current treatment of vasculitis}

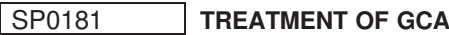

John H. Stone. USA

The treatment of giant cell arteritis (GCA) has taken a dramatic leap forward over the past 18 months, with the start of the era of interleukin- 6 inhibition for the treatment of this disease. For the first time in 70 years, rheumatologists now have a highly-effective alternative to continuous therapy with doses of glucocorticoids that are often unacceptably high, leading inevitably to steroid-related toxicity. Clinicians now have many questions about the optimal approach to treatment in this new era: When should IL-6 inhibition begin? How quickly should glucocorticoids be tapered? Should prednisone be stopped completely? Can tocilizumab ever be discontinued? How does one monitor for the possibility of disease flare? This session will address all of these questions using a data-driven approach, with reference to new data from the GiACTA trial

Disclosure of Interests: John H. Stone Grant/research support from: F. Hoffmann-La Roche, Genentech, Xencor, Consultant for: Chugain, F. Hoffmann-La Roche, Genentech, Xencor

DOI: 10.1136/annrheumdis-2019-eular.8594

\section{SP0182 TREATMENT OF AAV}

David Jayne. University of Cambridge, Department of Medicine, Cambridge, United Kingdom

Background: ANCA associated vasculitis is an autoimmune disease classified by clinical phenotype and serology. A genetic predisposition has been determined which differs between PR3-ANCA and MPO-ANCA patients. Experimental models have confirmed the pathogenicity of ANCA for certain aspects of pathology and have defined a role for alternative complement pathway activation but have failed to explain granuloma formation or gain insights into the origin of breakdown of tolerance. Therapy has emerged empirically to include the combination of high dose glucocorticoids and immunosuppression with B cell depletion, Rituximab, emerging as an alternative immunomodulator over the last 20 years. Studies have evaluated the role of Rituximab in induction, in refractory and relapsing disease and in the prevention of relapse and have explored the role of $b$ biomarkers in monitoring therapy. AAV patients continue to suffer poor outcomes especially if renal, cardiac or gastrointestinal features are present at diagnosis. Adverse event rates remain high and the majority of patients pursue a relapsing course. Inhibition of the alternative complement component $\mathrm{C} 5 \mathrm{a}$ is emerging as a new therapeutic opportunity.

Objectives: To define the outcomes and predictors for adverse outcomes in AAV. To review recent clinical trial data in the context of established guideline statements and to discuss the treatment of more complex clinical scenarios.

Methods: A description of current approaches to classification and subgrouping by severity. Review of recent clinical trial data and guidelines and application of learned knowledge to clinical scenarios.

Conclusion: AAV remains a disease with poor outcomes. There is a need for further understanding of the barriers to early diagnosis and access to specialist care. Treatment decisions are now well supported by evidence from clinical trials. Rituximab has had a major influence on current management strategies and is leading to improved outcomes and reduced glucocorticoid exposure. Complement inhibition is a potential new therapy for AAV.

\section{REFERENCES:}

[1] Jayne DR, Rasmussen N, Andrassy K, Bacon P, Tervaert JW, Dadoniene J, Ekstrand A, Gaskin G, Gregorini G, de Groot K, Gross W, Hagen EC, Mirapeix E, Pettersson E, Siegert C, Sinico A, Tesar V, Westman K, Pusey C. A randomized trial of maintenance therapy for vasculitis associated with antineutrophil cytoplasmic autoantibodies. N Engl J Med. 2003;349:36-44.

[2] De Groot K, Rasmussen N, Bacon PA, Tervaert JW, Feighery C, Gregorini G, Gross WL, Luqmani R, Jayne DR (senior author). Randomized trial of cyclophosphamide versus methotrexate for induction of remission in early systemic antineutrophil cytoplasmic antibody-associated vasculitis. Arthritis Rheum. 2005:52:2461-2469.
[3] Jayne DR, Gaskin G, Rasmussen N, Abramowicz D, Ferrario F, Guillevin L, Mirapeix E, Savage CO, Sinico RA, Stegeman CA, Westman KW, van der Woude FJ, de Lind van Wijngaarden RA, Pusey CD. Randomized trial of plasma exchange or high-dosage methylprednisolone as adjunctive therapy for severe renal vasculitis. J Am Soc Nephrol. 2007;18:2180-2188.

[4] de Groot K, Harper L, Jayne DR, Flores Suarez LF, Gregorini G, Gross WL, Luqmani R, Pusey CD, Rasmussen N, Sinico RA, Tesar V, Vanhille $\mathrm{P}$, Westman K, Savage CO. Pulse versus daily oral cyclophosphamide for induction of remission in antineutrophil cytoplasmic antibody-associated vasculitis: a randomized trial. Ann Intern Med. 2009;150:670-680.

[5] Hiemstra TF, Walsh M, Mahr A, Savage CO, de Groot K, Harper L, Hauser T, Neumann I, Tesar V, Wissing KM, Pagnoux C, Schmitt W, Jayne DR Mycophenolate Mofetil vs Azathioprine for Remission Maintenance in Antineutrophil Cytoplasmic Antibody-Associated Vasculitis: A Randomized Controlled Trial. JAMA. 2010;304:2381-8.

[6] Jones RB, Cohen Tervaert JW, Hauser T, Luqmani R, Morgan MD, Peh CA, Savage CO, Segelmark M, Tesar V, van Paassen P, Walsh D, Walsh M, Westman K, Jayne DR (senior author). Rituximab versus cyclophos phamide in ANCA-associated renal vasculitis. $N$ Engl $J$ Med 2010;363:211-220.

[7] Jones RB, Furuta S, Cohen Tervaert JW, Hauser T, Luqmani R, Morgan MD, Peh CA, Savage CO, Segelmark M, Tesar V, Jayne DR. Rituximab versus cyclophosphamide in ANCA-associated renal vasculitis: 2-year results of a randomised trial. Ann Rheum Dis. 2015;74(6):1178-82

[8] Yates M, Watts RA, Bajema IM, Cid MC, Crestani B, Hauser T, Hellmich B, Holle JU, Laudien M, Little MA, Luqmani RA, Mahr A, Merkel PA, Mills J, Mooney J, Segelmark M, Tesar V, Westman K, Vaglio A, Yalçindağ N, Jayne DR, Mukhtyar C. EULAR/ERA-EDTA recommendations for the management of ANCA associated vasculitis. Ann Rheum Dis. 2016 Sep;75 (9):1583-94.

[9] Hiemstra TF, Walsh M, Mahr A, Savage CO, de Groot K, Harper L, Hauser T, Neumann I, Tesar V, Wissing KM, Pagnoux C, Schmitt W, Jayne DR; European Vasculitis Study Group (EUVAS). Mycophenolate mofetil vs azathioprine for remission maintenance in antineutrophil ectoplasmic antibody associated vasculitis. JAMA. 2010 Dec 1;304(21):2381-8.

Disclosure of Interests: David Jayne Grant/research support from: David Jayne has received research grants from Chemocentryx, GSK, Roche/Genentech and Sanofi-Genzyme. He has received consultancy fees from Astra-Zeneca, Boehringer-Ingelheim, Chemocentryx, Chugai, GSK, Infla-RX, Insmed and Takeda DOI: 10.1136/annrheumdis-2019-eular.8509

\section{SP0183 DIAGNOSIS AND TREATMENT OF HCV RELATED VASCULITIS}

Peter Lamprecht. University of Lubeck, Department of Rheumatology and Clinical Immunology, Lubeck, Germany

Chronic hepatitis $\mathrm{C}$ virus ( $\mathrm{HCV}$ ) infection is the most common cause of cryoglobulinemic vasculitis. In contrast, non-cryoglobulinemic vasculitis is rare in chronic $\mathrm{HCV}$ infection. Cryoglobulinemic vasculitis is a systemic immune complex-mediated vasculitis predominantly affecting small vessels and associated with the presence of serum cryoglobulins, i.e. cold-precipitable immunoglobulins. HCV is a hepato- and lymphotropic virus. Notably, secondary transition from benign lymphoproliferative disease to malignant non-Hodgkin lymphoma $(\mathrm{NHL})$ as well as primary co-manifestation of cryoglobulinemic vasculitis and $\mathrm{NHL}$ has been reported in chronic hepatitis $\mathrm{C}$. While cryoglobulinemia is detected in $50 \%$ or more of the patients with chronic hepatitis $\mathrm{C}$, less than $5 \%$ develop related vasculitis. In this disorder, $\mathrm{HCV}$ induces clonal proliferation of memory phenotype marginal zone-like B-lymphocytes with restricted Ig heavy chain variable $\left(V_{H}\right)$ 1-69 gene expression encoding for the IgM rheumatoid factor (RF) WA idiotype. Monoclonal IgM RF binding to the $\mathrm{Fc}$ region of polyclonal IgG with anti-HCV reactivity facilitate the formation of cryoprecipitable multi-molecular immune-complexes. Cryoglobulins are preferentially deposited in tissues with high blood flow per unit mass of tis sues, e.g. skin, synovium, choroid plexus and glomerulus, where they bind to endothelial cells via the $\mathrm{C} 1 \mathrm{q}$ receptor.

Endothelial cryoglobulin deposition induces the activation and recruitment of circulating neutrophil granulocytes and other immune cells to the endothelial lesion eventually resulting in complement-consuming vasculitis.

The histopathologic changes in HCV-related vasculitis range from cutaneous leukocytoclastic vasculitis to severe necrotizing arteritis. Type I membranoproliferative glomerulonephritis is frequently found in patients with renal involvement. Clinical features of HCV-associated vasculitis comprise purpura, Meltzer's triad (purpura, arthralgia, asthenia), polyneuropathy, renal involvement and Raynaud`s 
phenomenon. Hemorrhagic alveolitis, interstitial lung disease, gastrointestinal vasculitis, cardiac involvement, osteosclerosis and hyperviscosity syndrome are less common manifestations. Diagnostic criteria have been developed for HCVassociated cryoglobulinemic vasculitis.

International therapeutic guidelines recommend treatment of HCV-related vasculitis to be guided according to the severity of disease. In patients with mild to moderate disease, interferon-free therapy regimens with direct acting antivirals (DAA) are considered as first-line treatment. In patients with severe manifestations, rituximab is given for the control of vasculitic manifestations, followed by HCV eradication using DAA. High rates of clinical responses and sustained virologic responses (SVR) have been reported for DAA treatment in HCV-associated cryoglobulinemic vasculitis. However, relapse of cryoglobulinemic vasculitis may occur in patients despite earlier treatment-induced clinical response and SVR. Persistence of clonal B-lymphocyte proliferation and perseverance of perturbations of the immune homeostasis have been shown in HCV-cured patients with relapse of cryoglobulinemic vasculitis.

Disclosure of Interests: None declared

DOI: 10.1136/annrheumdis-2019-eular.8525

SATURDAY, 15 JUNE 2019

09:00:00 - 10:30:00

\section{Workshop: \#ConnectToday and tomorrow: the campaigning continues}

\section{SP0184 DON'T DELAY, CONNECT TODAY IN FINLAND: A VIDEO TO PROMOTE EARLY DIAGNOSIS}

Maria Ekroth. Institute of Anatomy, Paracelsus Medical University, Imaging and Functional Musculoskeletal Research, Salzburg, Austria

Positive Encounter - Don't Delay Connect Today

Background: Too often people suffer the symptoms of rheumatoid arthritis for too long before they visit a doctor.

The positive encounter between physician and patient can lead to a good relationship, follow-up care and positive health outcomes. We conducted a survey about the need for a treatment plan and found that less than $30 \%$ of patients know their treatment plan and patients who do know their plan are better committed and more satisfied with their physicians. $72 \%$ of survey respondents who know their treatment plan are happy with their treatment as whole. Of the remainder, only $33 \%$ are satisfied.

\section{Objectives:}

1. The aim of this campaign is to illustrate and inform people of the symptoms of rheumatoid arthritis and encourage them to visit a doctor, enabling the doctor to assist the patient.

2. To give advice to patients on how to prepare for a doctor's appointment.

3. The campaign also includes a section directed at rheumatologists and rheumatology nurses, that advises on the importance of the encounter and the creation of the treatment plan.

4. To increase awareness about our association, and to recruit new members

Methods: Video for patients and the wider public. Video for rheumatologists and rheumatism professionals. Mailing of brochures on the importance of the treatment plan to all Finnish rheumatologists and arthritis treatment units. We also thanked doctors and attached a fruit gift card.

We sent flyers and posters to our member associations. Members have handed out materials directed at patients locally. They have distributed them to libraries, municipalities, sports centres... and given away fliers at the events.

Results: Patients have reported being better prepared for the visits and having written down important questions in advance. We achieved attention value amongst professionals and were invited to design a national treatment path with rheumatism professionals for children with JIA. All the main hospitals are involved and will start to use it. Free TV air time was offered for the patient video on the national main TV channel.

The Finnish Society for Rheumatology offered us the possibility of promoting our campaign at the Scandinavian Congress of Rheumatology.

Conclusion: The campaign was successful.

\section{REFERENCES:}

[1] www.youtube.com/watch?v=Y2_z8cxDvaA

[2] https://www.youtube.com/watch?v=vkDf7C-VPoY

[3] https://www.reumaliitto.fi/fi/reumaliitto/uutiset/reumaliiton-tilaisuus-eduskunnassa-viestit-vaaleihin-2019

[4] https://www.reumaliitto.fi/fi/hoidonlaatu

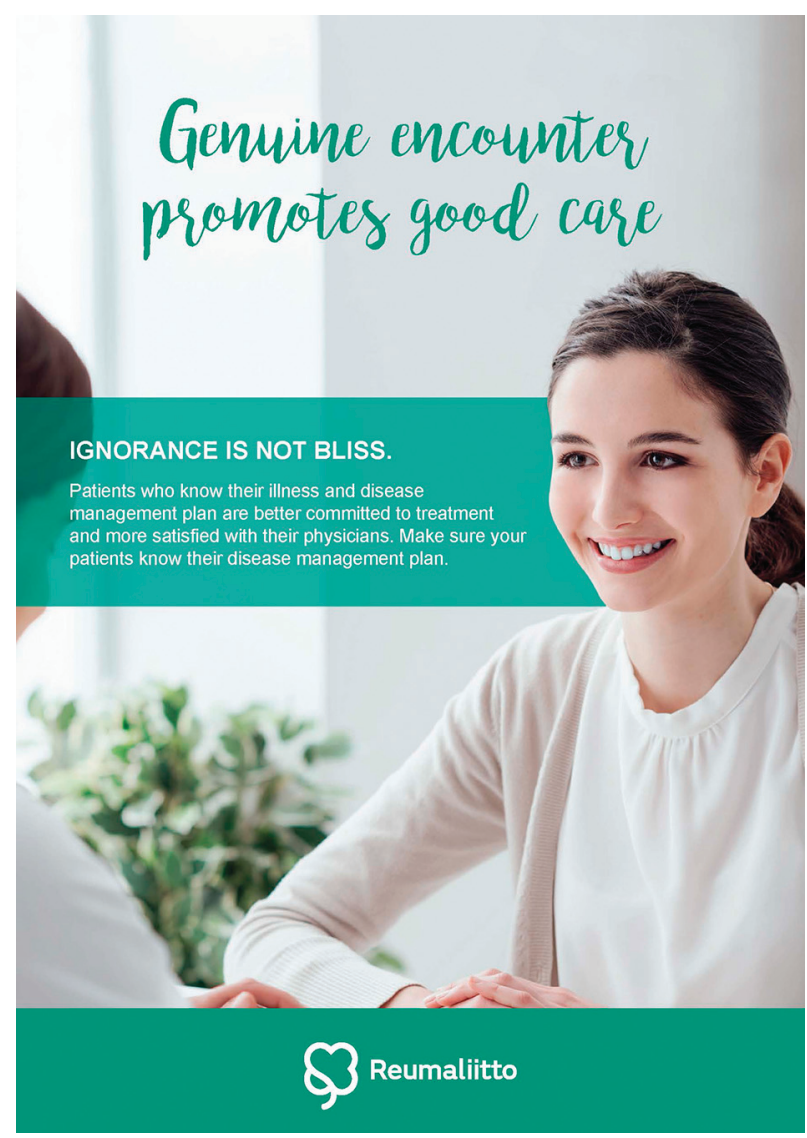

DISEASE MANAGEMENT PLAN INCREASES
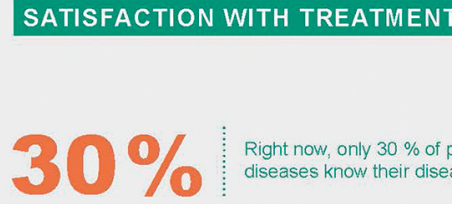

Right now, only $30 \%$ of people with rheumatic diseases know their disease management plan.

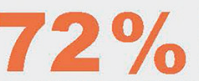

$72 \%$ of survey respondents who know their disease management plan are happy with their treatment as a whole. Of others, only $33 \%$ are satisfied.

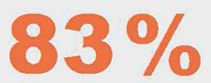

Over $83 \%$ of the patients who knew their disease management plan found their physician skilled, friendly and interested in the patient. They also thought that reception time was adequate.

The Finnish Rheumatism Association's web survey on the quality of care of rheumatic illnesses 2018. 1180 respondents.

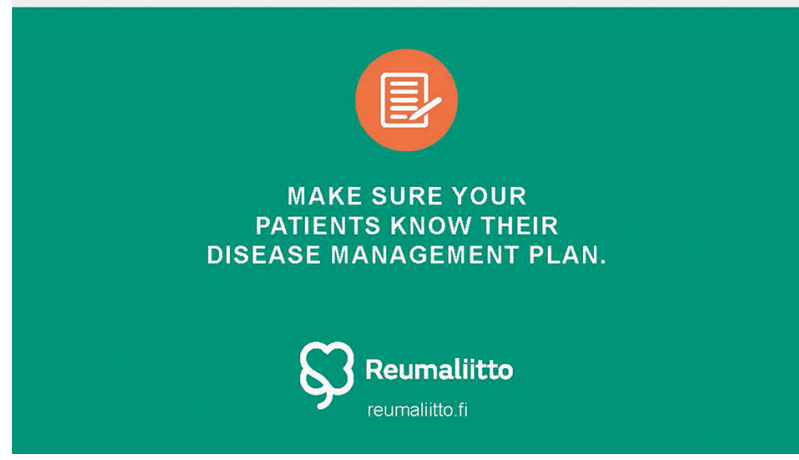

Disclosure of Interests: None declared DOI: 10.1136/annrheumdis-2019-eular.8467 